\title{
Olhando para a frente
}

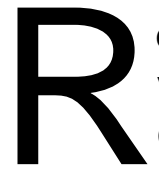

elutei bastante em aceitar o convite da nova Comissão de Publicação da Revista Medicina-RP para escrever um editorial imediatamente após minha saída da sua direção. Achava desnecessário e pretensioso fazer um balanço do trabalho realizado nos últimos seis anos na editoria da Revista, mas convenci-me da possível utilidade de fazer uma reflexão sobre o futuro, aproveitando as lições do passado e algumas do presente, auxiliado agora por uma confortável distância do problema. Aceitando como premissa consensual o modelo de uma publicação destinada prioritariamente a educação e atualização médica, distinta da divulgação primária de investigações científicas originais, a grande questão para o futuro é como avançar neste modelo, mantendo a qualidade do material publicado. No editorial de sua apresentação, a nova Comissão propõese a manter o formato atual da Revista, centrado em Simpósios temáticos, estimulando, em adição, " publicação de revisões por "experts", de introdução de teses, ...relatos de casos originais, resenhas críticas, notas prévias, cartas ao editor, pontos de vista e proposições teóricas e práticas". Infelizmente, entretanto, a resposta ao desafio de melhorar a qualidade da Revista não depende exclusivamente das boas intenções dos editores, mas também de fatores imponderáveis da vida acadêmica.Tomemos o exemplo dos Simpósios Temáticos, constituídos de um grupo de revisões em torno de um tema, ou das revisões isoladas, que, em conjunto, constituíram o principal conteúdo editorial da Revista nos últimos anos. Praticamente a totalidade das revisões e simpósios publicados tiveram características exclusivamente didáticas, isto é, sumarizaram e atualizaram o conhecimento de um tópico na área de atuação dos autores, os quais, entretanto, ti- veram mínima ou nenhuma participação na geração deste conhecimento. Mesmo quando tiveram, ou quando possuíam alguma experiência relevante na área, como uma grande casuística clínica, na maioria das vezes houve uma surpreendente resistência em incluir e destacar esta experiência, o que raramente conseguimos nestas revisões. Um Simpósio temático completo sobre doenças tropicais, por exemplo, deixou de ser publicado porque os autores, ainda que imersos em uma área de grande prevalência destas doenças, lidando com elas no dia-a-dia e publicando esta experiência na literatura, não conseguiram organizá-la e transmiti-la nas revisões. A mesma dificuldade pôde ser observada nos artigos originados da FMRP e, na maioria das vezes, não foi superada.

\section{INDEXAÇÃO: ONDE, COMO e POR QUÊ?}

Uma questão sempre presente é a da necessidade e do esforço necessário para indexar a Revista no Index Medicus (IM) e, conseqüentemente, no Medline. Fizemos duas tentativas, durante nossa gestão, ambas compreensivelmente mal-sucedidas diante do formato da Revista, escrita em português com predominância de artigos de revisão. Os poucos artigos originais com potencial interesse para uma audiência internacional, como os relatos de endemias regionais, não foram suficientes para sensibilizar o comitê do National Institutes of Health americano que julga as indexações. No dizer de um dos membros deste comitê, para a Revista ter alguma chance de ser indexada, seus artigos deveriam despertar, internacionalmente, um interesse tal que mobilizasse os leitores a traduzi-los para suas próprias línguas (ou para o inglês). A propósito, quantas vezes nos mobilizamos para tra- 
duzir para o português algum artigo indexado escrito em francês, alemão ou japonês? Uma das alternativas para propiciar a indexação da Revista no IM, discutida intensamente com a nova Comissão de Publicação e implícita no seu editorial, é o comissionamento de revisões autoritativas (certamente dois anglicismos!), de preferência escritas em inglês, em que um pesquisador experiente (ou um seu pós-graduando, aproveitando a introdução da tese) atualiza uma área do conhecimento destacando a contribuição do seu grupo. No passado, não conseguimos mobilizar a grande massa de pesquisadores da FMRP, principalmente das disciplinas básicas, para preparar estas revisões, apesar de não a termos procurado ativamente, como fizemos com as revisões didáticas. A verdade é que tanto uma como a outra requerem um esforço consideravelmente maior e mais complexo do que a preparação de um artigo científico convencional e este esforço nem sempre é adequadamente valorizado na análise da atividade acadêmica. A situação é bem refletida no dizer de um colega, para quem "só se escreve revisão para atender a pedido de um amigo muito chegado". Para complicar ainda mais a situação, está havendo uma certa pressão, vinda dos meios acadêmicos ingleses, para que as revisões e opiniões editoriais sigam estritamente certas regras metodológicas de coleta e análise de dados reunidas nas assim chamadas revisões sistemáticas (vide What are the benefits of editorials and non-systematic reviews?, BMJ 318: 135, 1999 e nosso editorial Anistia a ensaios clínicos no no Jan-Mar/98 desta Revista). Se aceitas, estas regras implicarão uma formidável reciclagem dos experts revisores, o que, a curto e médio prazo, significará grande redução na disponibilidade de revisões de qualidade, principalmente em nosso meio. Não está claro, entretanto, até que ponto esta exigência de revisões sistemáticas se aplicaria a todos os tipos de revisões ou só apenas às de intervenção terapêutica. Não estou convencido, realmente, de que a indexação no Index Medicus (para não falar no Current Contents, que é ainda mais restrito) seja vital para uma Revista com os objetivos e as característi- cas da Medicina-RP. Estou plenamente convencido, porém, de que ela não deve tentar alterar radicalmente suas características (priorizar artigos científicos originais em inglês, por exemplo) apenas para se adequar às exigências da indexação. Para propiciar uma fonte bibliográfica importante de atualização médica a estudantes, residentes e profissionais de língua portuguesa e espanhola, sua distribuição a cerca de 400 bibliotecas médicas da América Latina e sua presença no Índex Médico Latino-Americano (mais conhecido por LILACS, de Literatura Latino-Americana e do Caribe em Ciências da Saúde), além de outras bases de consulta, são claramente suficientes. Outras iniciativas para ampliar a penetração da Revista, como a inserção do texto integral na Internet, para consulta livre, e sua distribuição gratuita a hospitais filantrópicos do Estado, que iniciamos em nossa gestão, produzem seguramente mais resultados do que a simples indexação no IM.Suponhamos, entretanto, que a Revista resolva fazer um esforço para ser indexada no Index Medicus, sem alterar significativamente suas características editoriais. Para isto, convocaria todo o corpo docente da FMRP, "seus amigos muito chegados" e seus orientados para escrever revisões autoritativas em suas áreas de atuação e os docentes, médicos assistentes e residentes do HCFMRP para relatar os seus casos clínicos mais interessantes. Tudo isto em inglês, para evitar a barreira da língua no processo de indexação. Estou terminando, por exemplo, uma destas revisões, a pedido de um destes "amigos", para uma revista brasileira publicada totalmente em inglês, o que me tomou mais de um mês de trabalho (muitas vezes à noite $e$ em finais de semana) e a compilação de perto de 100 referências, além da pesquisa do meu grupo e de afiliados. Ao contrário das revisões didáticas, dirigidas a iniciantes e ao público em formação, as autoritativas se dirigem a uma audiência mais especializada, mais envolvida com investigação científica ou com medicina acadêmica e, portanto, beneficiar-se-iam de uma indexação mais ampla no Index Medicus. No caso da Medicina-RP, portanto, estas revisões seriam 
necessárias para se pleitear a indexação, mas esta seria também necessária para se manter 0 fluxo de boas revisões. Como manter este fluxo enquanto a indexação não vem? A única maneira é valorizar adequadamente as contribuições para a Revista, e não equipará-la com outras publicações sem corpo editorial nem qualquer indexação, como parece ocorrer atualmente no próprio seio da FMRP. A título de exemplo, no processo de mudança curricular para o Problem Based Learning numa escola médica pioneira do processo nos EUA, cada unidade didática preparada pelo corpo docente era equiparada, pelos órgãos de avaliação, a um trabalho científico completo publicado em uma revista indexada. Como mencionei acima, o esforço para indexação da Revista, ou para sua valorização, não pode envolver só seus editores, mas toda a comunidade acadêmica, incluindo sua direção e os órgãos de avaliação. Não tenho dúvidas de que a revista Medicina-RP deve ter a cara das duas instituições que representa, a Faculdade de Medicina e o Hospital das Clínicas da USP-RP. Para isto, deveria refletir em sua plenitude a riqueza, tanto da investigação científica, como da prática médica realizada nestas instituições. Assim, além de continuar a publicar os resumos de teses defendidas pelos pós-graduandos da FMRP e as revisões didáticas dos docentes, deveria ter, como discutimos acima, resumos ou trabalhos originais de iniciação científica, revisões autoritativas centradas em pesquisas realizadas localmente, muitos casos e artigos clínicos originados do HCRP e outras secções planejadas mas nunca concretizadas (Atualização Diagnóstica, Atualização Terapêutica, Discussões Clínicas, Controvérsias Médicas, Novas Hipóteses Científicas, Medicina Básica para o Clínico, Resenhas de Livros, etc., etc.). Para isto se tornar realidade, o corpo docente tem que se mobilizar e o relato de toda esta atividade na Revista tem que ser mais valorizado do que é atualmente.

\section{INDEPENDÊNCIA EDITORIAL EM RISCO}

Imaginem a seguinte situação hipotética: a revista Medicina-RP publica um trabalho, realizado pela Escola de Comunicações e Artes da USP, mostrando que os residentes do HCFMRP, em sua maioria, se opõem ao atendimento de pacientes privados e conveniados dentro da instituição. Considerando a publicação politicamente inoportuna e tendenciosa em um momento particularmente sensível, a administração do HCRP afasta o editor da Revista e solicita à Congregação a indicação de um novo nome. Os outros membros da Comissão Editorial lamentam o fato, publicam um manifesto defendendo a independência dos editores, mas permanecem em seus cargos e a Congregação, mesmo reconhecendo as qualidades e os serviços prestados pelo editor, aponta um substituto. Ficção absoluta ou absurdo possível?Por muito menos, o editor do JAMA, Journal of the American Medical Association, George Lundberg, que gozava de imenso prestígio e estava no cargo há 14 anos, foi demitido há poucos meses. O motivo foi a publicação, no número de 20/jan/99, de uma pesquisa, realizada por pesquisadores da Universidade de Indiana, mostrando que a maioria dos estudantes universitários americanos não consideravam o contato oro-genital como "ter praticado sexo com outra pessoa" ("Would you say you "Had Sex" if...?", JAMA 281: 275, 1999). O diretor executivo da AMA, responsável pela demissão, justificou-a declarando que a decisão de publicar o artigo "comprometeu a tradição histórica e a integridade do JAMA introjetando-o inapropriadamente e indesculpavelmente em um debate político importante (o impeachment de Bill Clinton) que não nem nada a ver nem com ciência nem com medicina". O website da Associação Mundial de Editores Médicos (WAME) ficou entupido com mensagens de solidariedades ao Dr. Lundgren, seus colegas da Comissão Editorial do 
JAMA publicaram um artigo defendendo a independência editorial, mas nenhum entregou seu cargo e a AMA está procurando um novo editor para o JAMA, se já não o encontrou.Descontando o fato de que o diretor da AMA tinha o direito legal de afastar o editor do JAMA, o que seria questionável se ocorresse na Medicina-RP, esta estória ilustra bem a grande tentação do patrocinador da publicação de controlar e exercer censura sobre o material publicado, tornando a independência editorial um valor que deve ser permanente e ativamente preservado. Felizmente, pelo que sei, ela nunca foi arranhada na Medicina-RP e esperamos que nunca o seja.

\section{OS MEIOS E OS FINS NA UNIVERSIDADE}

No tópico acima do último editorial da Revista ("O mundo acadêmico pode ser uma selva" Medicina-RP jul-set/98) referi-me `a aposentadoria de professores pelo Al-5 e ao descredenciamento do HCFMRP para atendimento médico dos servidores da USP como uma das "muitas situações obtusamente irracionais e injustas"...em que "pôde-se vislumbrar a mão de personalidades universitárias maquiavelicamente poderosas e preconceituosas".

Recebi do Prof. Erasmo M. Castro de Tolosa, Superintendente do Hospital Universitário da USP/SP, órgão central do sistema de saúde da universidade, a seguinte manifestação sobre a matéria: "É difícil acolher um exemplo em cuja raiz existe engano. Todos os defeitos apontados por Vossa Senhoria, creditados no corporativismo, meandros obscuros, manipulação de processos, e benefício pessoal de pequena parcela de professores, foram escolmados do Convênio do SISUSP com a FAEPA (entida- de de direito privado) que teve a oportunidade de participar de processo licitatório transparente. $A$ evolução da qualidade do atendimento e os dados do custo atual e comparativamente ao que vinha sendo praticado estão à disposição de todos. Se os dirigentes universitários, nos quais incluo Vossa Senhoria, ao invés de divulgarem conceitos e notícias inverídicas sobre a questão, tomarem a decisão de atenderem no Hospital das Clínicas da Faculdade de Medicina de Ribeirão Preto todos os cadastrados do SISUSP, sem ônus para a Universidade, dentro do SUS com a qualidade USP, estariam nesse setor, escolmando da relação USP/SISUSP dos defeitos e procedimentos não recomendáveis, tão bem citados em seu editorial".

Em sua manifestação, o polêmico professor notoriamente revela-se adepto do verbo "escolmar" e da medicina filantrópica (pelo menos para o HCFMRP) e veste a carapuça no caso do rompimento do convênio SISUSP-FAEPA. Resta comprovar que a "qualidade USP" está melhor servida pela empresa de medicina de grupo que atualmente atende os servidores do que pelo HCFMRP, como sugere o Prof. Tolosa. E esperar que algum contemporâneo do Prof. Gama e Silva, ex-reitor da USP e Ministro da Justiça na edição do Al-5, venha também defender a aposentadoria dos professores universitários em 1969.

Prof. Dr. Júlio C. Voltarelli

Editor da Revista Medicina no período de julho de 1992 a dezembro de 1998.

Professor Visitante, The Scripps Research Institute, San Diego, CA, USA. E-mail: jcvoltar@scripps.edu 